\title{
Receptor Interactions of a Series of Imidazolines: Comparison of the Alpha2-Adrenoceptors between the Rabbit Vas Deferens and Guinea Pig lleum
}

\author{
Fukio KONNO, Masataka KUSUNOKI and Issei TAKAYANAGI* \\ Department of Chemical Pharmacology, Toho University School of Pharmaceutical Sciences, \\ Miyama. Funabashi, Chiba 274. Japan
}

Accepted March 7, 1987

\begin{abstract}
A series of imidazolines and norepinephrine were used to characterize

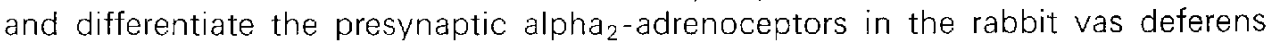
and the guinea pig ileal longitudinal muscle using pharmacological procedures. Based on pEC50-values (the negative log of the $50 \%$ effective concentration) for each imidazoline, a rank order of potency of $p$-aminoclonidine >oxymetazoline $\geqq$ clonidine $>$ naphazoline $>$ phentolamine was obtained in the rabbit vas deferens and an order of $p$-aminoclonidine>clonidine >naphazoline >oxymetazoline was obtained in the guinea pig ileum. In the rabbit vas deferens, phentolamine. which is generally considered to be a competitive alpha ${ }_{1}$ - and alpha ${ }_{2}$-adrenoceptor antagonist, acted as a full alpha ${ }_{2}$-adrenoceptor agonist. The dissociation constants of oxymetazoline and yohimbine were significantly lower in the rabbit vas deferens than in the guinea pig ileum. These results suggest that the presynaptic alpha ${ }_{2}-$ adrenoceptors in these tissues are different. Furthermore. the $\mathrm{pK}_{\mathrm{B}}$-value of yohimbine against norepinephrine was significantly one log unit lower than those obtained using a series of imidazolines. Data from our studies add to increasing evidence of the existence of high and low affinity binding sites on the alpha - $^{-}$ adrenoceptors in the rabbit vas deferens.
\end{abstract}

The first proposal of the subclassification of alpha-adrenoceptors into alpha ${ }_{1}$ and

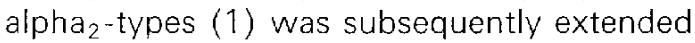
by other investigators (2-4). It is fundamentally accepted that alpha ${ }_{1}$-adrenoceptors are located in postsynaptic sites, while alpha ${ }_{2}$ adrenoceptors are situated presynaptically, although there is increasing evidence that postsynaptic alpha ${ }_{2}$-adrenoceptors are present in some vascular smooth muscles (57). The presynaptic alpha 2 -receptors are further defined by the function that they inhibit transmitter release from adrenergic, cholinergic and serotoninergic neurones as pointed out (8).

Although the general characteristics of presynaptical alpha 2 -adrenoceptors are the same, there are some observations indicating

\footnotetext{
* To whom all correspondence should be addressed.
}

a possibility of discriminating between these receptors with different species or different drugs. For example, Alabaster et al. (9) suggested that alpha $a_{2}$-adrenoceptors are a heterogeneous population between different species rather than between different tissue types or locations. Furthermore, several investigators suggested that the recognition sites of some alpha $a_{2}$-adrenoceptor agonists with an imidazoline moiety differed from those with phenylethylamines (10-13).

In the rabbit vas deferens, Adebanjo and Ambache (14) first found that the electrically induced twitch responses were completely inhibited by the presence of phentolamine, an alpha - and alpha $_{2}$-adrenoceptor antagonist. Ennis and Lattimer (15) suggested that the inhibitory effects of phentolamine in the rabbit vas deferens were antagonized by yohimbine, an alpha ${ }_{2}$-adrenoceptor antag- 
onist, in a competitive manner, but were not inhibited by indoramin, an alpha, adrenoceptor antagonist. These results suggested that phentolamine acted as an alpha ${ }_{2}-$ adrenoceptor agonist in the rabbit vas deferens. However, pharmacological characterizations of the alpha $a_{2}$-adrenoceptors in the rabbit vas deferens are poorly understood.

In classification studies of drugs and their receptors, relative potency of a series of agonists, comparison of the agonist affinity and comparison of relative efficacies of a series of agonists offers useful information, as does quantification of the competitive antagonist affinity $(16-18)$. In the present study, we are attempting to distinguish further between the alpha ${ }_{2}$-adrenoceptors in the rabbit vas deferens and the guinea pig ileal longitudinal muscle which is commonly used as an isolated preparation for the study of alpha ${ }_{2}$-adrenoceptors, by using a series of agonists of the imidazoline class. By studying a series of agonists, we are attempting to

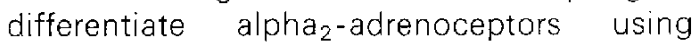
several methods of receptor classification as mentioned above.

\section{Materials and Methods}

Rabbit vas deferens: Male albino rabbits weighing 2.0 to $3.0 \mathrm{~kg}$ were killed by bleeding from the neck, and the vas deferens was rapidly removed. The prostatic half of the vas deferens was mounted in a $20 \mathrm{ml}$ organ bath filled with Krebs' solution kept at $37^{\circ} \mathrm{C}$ and gassed with $5 \% \mathrm{CO}_{2}$ and $95 \% \mathrm{O}_{2}$. The composition of the solution was (in $\mathrm{mM}$ ): $\mathrm{NaCl}$. 118: $\mathrm{KCl}, 4.7 ; \mathrm{KH}_{2} \mathrm{PO}_{4}, 1.19 ; \mathrm{MgCl}_{2}, 1.2$; $\mathrm{CaCl}_{2}, 2.54 ; \mathrm{NaHCO}_{3}, 25$; and glucose, 11 . Some of the agonists studied increased the resting tension of the vas deferens. Prazosin $\left(10^{-6} \mathrm{M}\right)$ was included in the Krebs' solution in these experiments (19). The fact that this concentration of prazosin abolishes the increase in resting tension produced by the postsynaptic agonistic effect without inhibiting stimulation responses indicates that the agonists and prazosin are acting at an extrasynaptic site. The solution also contained propranolol $\left(10^{-6} \mathrm{M}\right)$ to block betaadrenoceptors (20). The vasa deferentia were stimulated electrically via two platinum ring electrodes $(3 \mathrm{~mm}$ in diameter and $5 \mathrm{~mm}$ interval) with a rectangular pulse of $0.3 \mathrm{msec}$ duration, supramaximal voltage and a frequency of $0.1 \mathrm{~Hz}$. Tissues were maintained under a resting tension of $500 \mathrm{mg}$ and allowed to equilibrate for at least $30 \mathrm{~min}$. with changes of bathing fiuid at $10 \mathrm{~min}$ intervals. Responses of the vasa deferentia were isometrically recorded by a force displacement transducer.

Ileal longitudinal muscle of guinea pig: Guinea pigs weighing 300 to $400 \mathrm{~g}$ were kilied, and the ileum was rapidly removed. The first $10 \mathrm{~cm}$ of ileum nearest the ileocecal junction was discarded. The Iongitudinal muscle with myenteric plexus was isolated by carefully slipping an ileal segment over a tapering glass rod (21) and placed in Krebs' solution. Pieces ( 20 to $30 \mathrm{~mm}$ ) of the longitudinal muscle strips were suspended in a $20 \mathrm{ml}$ organ bath filled with Krebs' solution kept at $37^{\circ} \mathrm{C}$ and gassed with $5 \% \quad \mathrm{CO}_{2}$ and $95 \% \mathrm{O}_{2}$. The preparations were allowed to equilibrate for at least $30 \mathrm{~min}$ under $500 \mathrm{mg}$ tension. Electrical field stimulation was carried out by passing a rectangular pulse of 0.1 msec duration, supramaximal voltage and a frequency of $0.1 \mathrm{~Hz}$. Responses were recorded isometrically as described above.

Concentration-response curves: After the equilibration. several cumulative concentration-response curves for norepinephrine were determined by increasing the bath concentrations. In each preparation, when the last two concentration-response curves were similar, all subsequent results were compared with the last of these curves.

After the control concentration-response curves of norepinephrine were obtained, successive cumulative concentration-response curves of other agonists were determined, and the agonistic activities of drugs were expressed as pEC50-values, the negative log molar concentration which produced $50 \%$ of the maximum inhibitions obtained from individual concentration-response curves. The intrinsic activities (i.a.) of agonists were expressed as a ratio between the maximum response to a test drug and that to norepinephrine. The antagonistic potency of each antagonist was measured against each agonist. After determining the control concentration-response curve of each agonist, the 
preparations were equilibrated with a competitive antagonist for $20 \mathrm{~min}$. Concentrationresponse curves were then obtained in the presence of the antagonist and the procedure repeated with a higher concentration of antagonist in the same preparation. Unlike other agonists, it was extremely difficult to wash out phentolamine from the rabbit vas deferens. Therefore, to avoid the residual effects of this agonist, the paired vasa deferentia from the same rabbit were mounted individually in separate organ baths containing Krebs' solution. One was used as a control preparation and the other as a competitive antagonist treated preparation.

Dissociation constant: Apparent dissociation constants $\left(K_{R}\right)$ for antagonists were determined by the concentration-ratio method described by Furchgott (1972) (16):

$$
K_{\mathrm{B}}=[\mathrm{B}] /(\mathrm{cr}-1)
$$

where $\mathrm{cr}$ is equieffective concentration-ratio obtained from the ratio of the concentration that produced 50 percent of maximum response to agonists in the presence and absence of antagonist and [B] is the molar concentration of an antagonist.

In order to estimate the dissociation constants of agonists, the alpha ${ }_{2}$-adrenoceptors were partially blocked by benextramine, an irreversible blocker of alpha ${ }_{2}$-adrenoceptors (22). After determination of the control concentration-response curves of agonists, the preparations were treated with $10^{-6} \mathrm{M}$ of benextramine for $30 \mathrm{~min}$. The preparations were then allowed to re-equilibrate for 60 min, with repeated washing every $10 \mathrm{~min}$, and cumulative concentration-response curves of agonists were determined. The dissociation constant $\left(K_{A}\right)$ of the agonist was calculated from the following equation (23):

$$
1 /[A]=1 / q\left[A^{\prime}\right]+(1-q) / q K_{\Lambda}
$$

where $[A]$ and $\left[A^{\prime}\right]$ are corresponding equieffective concentrations of the agonist before and after irreversible blockade of a fraction of alpha ${ }_{2}$-receptors with benextramine and $q$ is the fraction of remaining active receptors. If $1 /$ [A] was plotted versus $1 /\left[\mathrm{A}^{\prime}\right]$ and a straight line fitted to the data by linear regression analysis, the dissociation constant, $K_{A}$ was obtained by the following equation:

$$
K_{A}=(\text { slope }-1) / \text { intercept }
$$

Drugs used: I-Norepinephrine bitartrate (Wako-Junyaku), $p$-aminoclonidine hydrochloride (Funakoshi), clonidine hydrochloride (Tokyo-Kasei), naphazoline hydrochloride (Sigma), oxymetazoline hydrochloride (Sigma), vohimbine hydrochloride (Wako-Junyaku). DL-propranolol hydrochloride (Sig$\mathrm{ma}$ ), benextramine tetrahydrochloride (Sigma), prazosin hydrochloride (Pfizer) and phentolamine methanesulfonate (Ciba Geigy). The other chemicals used were of analytical grade. All drugs were used as solutions in distilled and deionized water.

\section{Results}

Comparison of agonistic activities: In a preliminary experiment, tetrodotoxin $\left(10^{-7} \mathrm{M}\right)$ completely abolished the electrically stimulated contractions in the rabbit vas deferens and the guinea pig ileal longitudinal muscle. indicating that the contractions are not due to direct stimulation of the smooth muscle.

Concentration-response curves for a series of imidazolines in the rabbit vas deferens and the guinea pig ileal longitudina! muscle are presented in Figs. 1 and 2, respectively. In the rabbit vas deferens, the series of imidazolines are full agonists relative to norepinephrine. while in the guinea pig ileum,

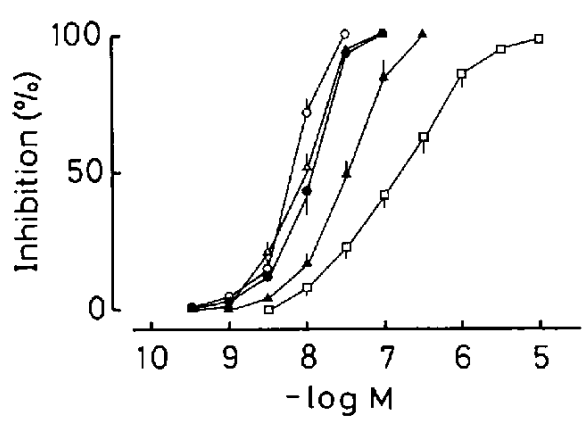

Fig. 1. Concentration-response curves for a series of imidazolines in rabbit vas deferens. Each point represents a mean with S.E. of 5 to 10 experiments. $\checkmark$ : o-aminocionidine. 0 : clonidine, $\triangle$ : oxymetazoline, $\boldsymbol{\Delta}$ : naphazoline and $\square$ : phentolamine. Responses are expressed on the ordinate scale as a percentage of the maximum response to norepinephrine $\left(3 \times 10^{-4} \mathrm{M}\right)$ and plotted against negative $\mathrm{log}$ molar concentrations of drugs on the abscissa scale. 


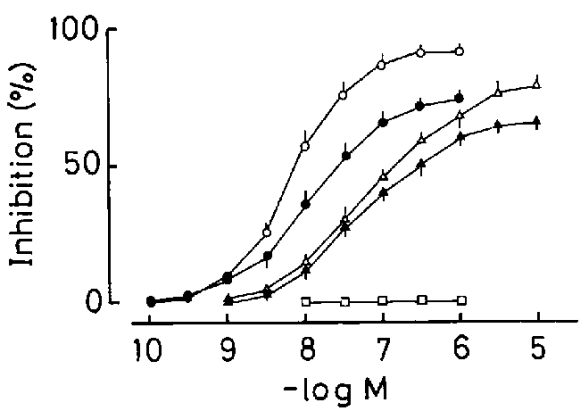

Fig. 2. Concentration-response curves for a series of imidazolines in guinea pig ileal longitudinal muscle. Each point represents a mean with S.E. of 6 to 10 experiments. O: p-aminoclonidine, clonidine. $\triangle$ : oxymetazoline, $\boldsymbol{\Delta}$ : naphazoline and $\square$ : phentolamine. Responses are expressed on the ordinate scale as a percentage of the maximum response to norepinephrine $\left(10^{-5} \mathrm{M}\right)$ and plotted against negative log molar concentrations of drugs on the abscissa scale.

clonidine, naphazoline and oxymetazoline depressed the twitch response partially, suggesting that they behaved as partial agonists. On the other hand. $p$-aminoclonidine acted as a full agonist in this tissue. Phentolamine also acted as a full agonist in the rabbits, but the drug did not show any agonistic activities in the guinea pigs. Phentolamine produced parallel and concentration dependent shifts of the clonidine concentration-response curves without a decrease in the maximum response, indicating a competitive antagonist $\left(\mathrm{pK}_{\mathrm{B}}\right.$-value, 8.74t 0.21, a mean with S.E. of 6 experiments) (Fig. $3)$. Important characteristics of the concentration-response curves for imidazolines in the

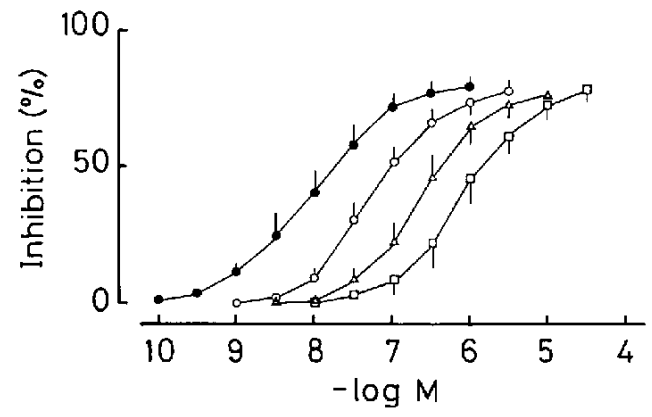

Fig. 3. Antagonism between clonidine and phentolamine in guinea pig ileal longitudinal muscle. Each point represents a mean with S.E. of 6 experiments. Clonidine alone (O) and with phentolamine. $10^{-8} \mathrm{M}(\mathrm{O}), 3 \times 10^{-8} \mathrm{M}(\mathrm{A})$ and $10^{-7} \mathrm{M}(\square)$. Responses are expressed on the ordinate scale as a percentage of the maximum response to norepinephrine $\left(10^{-5} \mathrm{M}\right)$ and plotted against negative log molar concentration of clonidine on the abscissa scale.

rabbit vas deferens and the guinea pig ileal longitudinal muscle are listed in Table 1.

Relative potencies based on the pEC50values of the series of imidazolines differed markedly between the two tissues. One major difference we have observed between the two tissues is that in the rabbit, oxymetazoline is approximately equieffective to $p$ aminoclonidine and clonidine, whereas in the guinea pig. oxymetazoline is approximately 10 -fold less potent than $p$-aminoclonidine. Furthermore, the intrinsic activities of imidazolines range from 0.98 to 1 in the rabbit and from 0 to 0.98 in the guinea pig.

Comparison of the dissociation constants of agonists: The dissociation constants for $p$ -

Table 1. The pEC50-values and the intrinsic activities of a series of imidazolines in rabbit vas deferens and guinea pig ileal longitudina! muscle

\begin{tabular}{lcccc}
\hline & \multicolumn{2}{c}{ Guinea pig ileum } & \multicolumn{2}{c}{ Rabbit vas deferens } \\
\hline p-Aminoclonidine & pEC50 & i.a. & pEC50 & i.a. \\
Clonidine & $8.12 \pm 0.08$ & $0.98 \pm 0.04$ & $8.17 \pm 0.04$ & 1 \\
Naphazoline & $7.93 \pm 0.12$ & $0.73 \pm 0.04$ & $7.95 \pm 0.06$ & 1 \\
Oxymetazoline & $7.31 \pm 0.19$ & $0.64 \pm 0.02$ & $7.44 \pm 0.11$ & 1 \\
Phentolamine & $7.14 \pm 0.05^{*}$ & $0.79 \pm 0.05$ & $8.00 \pm 0.08$ & 1 \\
\hline
\end{tabular}

Each value represents a mean with S.E. of 5 to 10 experiments. *: significantly different from the corresponding $\mathrm{PEC} 50$ value of the drug in the rabbit vas deferens at $P<0.05$. i.a.: intrinsic activity of the drug expressed as the ratio of the maximum response to the test drug against that to norepinephrine. a reference drug. 
aminoclonidine and oxymetazoline were determined by the method of Furchgott and Bursztyn (1967) (23) in both tissues using benextramine to block irreversibly a proportion of the alpha ${ }_{2}$-adrenoceptors. The $p K_{A^{-}}$ values which were expressed as the negative $\log$ of the dissociation constant of the agonist are shown in Table 2. The $p K_{A^{-}}$ value of $p$-aminoclonidine in the rabbit vas deferens was practically equal to that in the guinea pig ileal longitudinal muscle, while the $\mathrm{pK}_{\mathrm{A}}$-value of oxymetazoline was significantly lower in the rabbit than in the guinea pig.

Comparison of antagonistic activities: The inhibition of the twitch responses of the rabbit vas deferens by phentolamine was competitively antagonized by yohimbine $\left(3 \times 10^{-7} \mathrm{M}\right.$ and $3 \times 10^{-6} \mathrm{M}$ ) (Fig. 4). The inhibitions by other imidazolines of the twitch responses in both tissues were also competitively antagonized by yohimbine. The $p K_{B}$-values of yohimbine against a series of imidazolines in both tissues are summarized in Table 3. In the rabbit vas deferens, $\mathrm{pK}_{\mathrm{B}^{-}}$ values of yohimbine against a series of imidazolines were similar to each other. The $\mathrm{pK}_{\mathrm{B}}$-values of yohimbine in the guinea pig ileum were also the same. However, the $\mathrm{pK}_{\mathrm{B}}$-values of yohimbine in the rabbit were significantly lower than those in the guinea pig.

Comparison of antagonistic activity of yohimbine against norepinephrine in the rabbit vas deferens: After a 20 min incubation with $3 \times 10^{-6} \mathrm{M}$ of yohimbine, the concentration-response curves to norepinephrine in the rabbit were shifted in a parallel manner to the right with little or no change in the maximum responses, but the concentration-

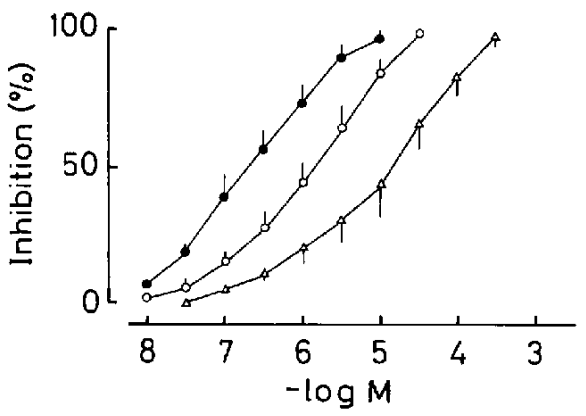

Fig. 4. Antagonism between phentolamine and yohimbine in rabbit vas deferer.s. Each point represents a mean with S.E. of 6 to 12 experimerits. Phentolamine alone (O) and with yohimbine, $3 \times 10^{-7} \mathrm{M}(\mathrm{O})$ and $3 \times 10^{-6} \mathrm{M}(\Delta)$. Responses are expressed on the ordinate scale as a percentage of the maximum response to norepinephrine $\left(3 \times 10^{-4}\right.$ M) and plotted against negative log molar concentration of phentolamine on the abscissa scale.

Table 2. The $p K_{A}$-values of $\rho$-aminoclonidine and oxymetazoline in rabbit vas deferens and guinea pig ileal longitudinal muscle

\begin{tabular}{lcc} 
& \multicolumn{2}{c}{$p K_{A}$ values } \\
& Guinea pig ileum & Rabbit vas deferens \\
P-Aminoclonidine & $7.88 \pm 0.15$ & $7.91 \pm 0.29$ \\
Oxymetazoline & $6.99=0.20^{*}$ & $7.74 \pm 0.74$ \\
\hline
\end{tabular}

Each value represents a mean with S.E. of 5 to 6 experiments. *: significantly different from the corresponding $p K_{A}$ value of the drug in the rabbit vas deferens at $P<0.05$.

Table 3. The $\mathrm{pK}_{\mathrm{B}}$-values of yohimbine against a series of imidazolines in rabbit vas deferens and guinea pig ileal longitudinal muscle

\begin{tabular}{lcc} 
Agonists & \multicolumn{2}{c}{ pKn values of yonimbine } \\
Clonidine & Guinea pig ileum & Rabbit vas deferens \\
\cline { 2 - 3 } Naphazoline & $8.05 \pm 0.06^{*}$ & $7.06 \pm 0.05$ \\
Oxymetazoline & $8.05 \pm 0.15^{*}$ & $7.12 \pm 0.14$ \\
Phentolamine & $7.97 \pm 0.05^{*}$ & $7.14 \pm 0.06$ \\
\hline
\end{tabular}

Each value represents a mean with S.E. of 6 to 8 experiments. ": significantly different from the corresponding $\mathrm{pK}_{\mathrm{B}}$ value of the drug in the rabbit vas deferens at $\mathrm{P}<0.05$. 


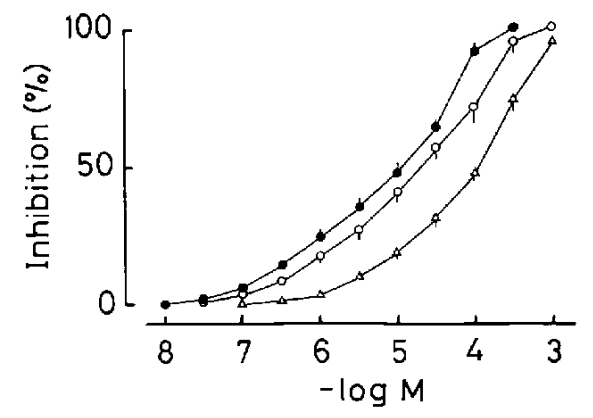

Fig. 5. Antagonism between norepine hrine and yohimbine in rabbit vas deferens. Each point is represents a mean with S.E. of 7 experiments. Norepinephrine alone (O) and with yohimbine. $3 \times 10^{-7} \mathrm{M}(\mathrm{O})$ and $3 \times 10^{-6} \mathrm{M}(\mathrm{A})$. Responses are expressed on the ordinate scale as a percentage of the maximum response to norepinephrine $\left(3 \times 10^{-4}\right.$ M) and plotted against negative log molar concentration of norepinephrine on the abscissa scale.

response curves to norepinephrine were only slightly influenced by $3 \times 10^{-7} \mathrm{M}$ of yohimbine which was a dose that clearly shifted the curves of a series of imidazolines (Fig. 5). The $p K_{B}$-value of yohimbine against norepinephrine in the rabbit vas deferens was $6.18 \pm 0.09$ (a mean with S.E. of 7 experiments). This value was significantly one log unit lower than those values against imidazolines.

\section{Discussion}

Norepinephrine and acetylcholine released in response to nerve impulses interacts with specific receptors that are located in the membranes of postsynaptic cells and triggers the physiological responses of the effector organs. The presynaptic alpha ${ }_{2}$-adrenoceptors, which are probably located in the adrenergic and cholinergic nerve terminals, modulate transmitter release. In fact, Belis et al. (24) demonstrated that yohimbine, an alpha $a_{2}$-adrenoceptor selective antagonist, was found to enhance release of $\left[{ }^{3} \mathrm{H}\right]$ norepinephrine from the rabbit vas deferens. Furthermore, by measurement of acetylcholine release from guinea pig ileum, it has been

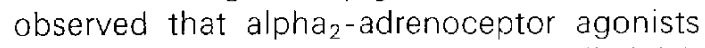
such as norepinephrine and clonidine diminish the output of the cholinergic transmitter (3).

It is generally accepted that receptors for neurohumoral substances exist in multiple forms and vary widely in both density and distribution in different tissues. Current knowledge also suggests that a!pha adrenoceptors are a heterogenous population of receptors based on the radioligand binding technique and a comparison of the potency of alpha ${ }_{2}$-adrenoceptor antagonists (9-11. 25-28). The classification of receptor types by radioligand binding assay, however, can sometimes be misleading since not only nonfunctional sites can be labelled in certain tissues but also many factors can alter the characteristics of binding in membrane preparations. In attempt to circumvent these problems, it is necessary for functional tests to be carried out to assess the characterization of receptors.

Phentolamine is generally considered to be a competitive alpha ${ }_{1}$ and alpha $a_{2}$-adrenoceptor antagonist without any agonistic activity. However, in the rabbit vas deferens, phentolamine can act as a full agonist at presynaptic alpha 2 -adrenoceptors $(14,15)$. These results lead to the possibility that alpha $a_{2}$-adrenoceptors in the rabbit vas deferens are different from those in other peripheral tissues. Currently, the isolated transmurally stimulated guinea pig ileum longitudinal muscle preparation is widely regarded as a valid test system for the analysis of alpha $a_{2}$-agonists and antagonists (20, 28, 29). In the present study, we attempted to differentiate alpha $a_{2}$-adrenoceptors in the rabbit vas deferens and the guinea pig ileal longitudinal muscle using several pharmacological methods of receptor classification as mentioned above.

Relative potencies of agonists is an effective method for classifying receptors (1618). In the present study, the relative potencies of a series of imidazolines, which were based on pEC50-values obtained from their concentration-response curves, differed between the rabbit and the guinea pig. Based on the pEC50-values for each compound. a rank order of potency of $p$-aminoclonidines oxymetazoline $\geq$ clonidine $>$ naphazoline $>$ phentolamine was obtained in the rabbit vas deferens, and an order of $p$-aminoclonidine $>$ clonidine >naphazoline >oxymetazoline was obtained in guinea pig ileum. Phentolamine 
had no agonistic activity in the guinea pig. In addition, the intrinsic activities of imidazolines range from 0.98 to 1 in the rabbit and from 0 to 0.98 in the guinea pig. Differences in intrinsic activities between tissues could result from differences in receptor number or differences in the efficiency of coupling between occupancy and response. and unlikely to reflect differences in receptor types $(17,18)$. However, phentolamine acted as a full agonist in the rabbit, but acted as a competitive antagonist in the guinea pig. This fact cannot account for a difference in receptor number or coupling and suggest that the relative efficacies vary considerably among these compounds in both tissues. These results indicate that the alpha adrenoceptors in these tissues are not identical. Furthermore, a useful method for differentiating receptors is comparison of dissociation constants of agonists and antagonists (16-18). When the respective affinities of several agonists and antagonists are the same in different tissues, it is likely that the drugs are interacting with the same receptor population. Conversely, differences in affinities imply interaction with different receptor populations. The negative log of the dissociation constant, $\mathrm{pK}_{\Lambda}$-value, of oxymetazoline obtained herein by the partial irreversible blockade of alpha $a_{2}$-adrenoceptors with benextramine in the rabbit vas deferens was significantly lower than in the guinea pig ileum. Moreover, in the rabbit vas deferens, $\mathrm{pK}_{\mathrm{B}}$-values of yohimbine against a series of imidazolines were also significantly lower than those in the guinea pig ileum. These results also suggest that the alpha 2 -adrenoceptors in the rabbit vas deferens are different from those in the guinea pig ileum.

Finally, many investigators suggested the possibility that the recognition sites of some alpha $_{2}$-agonists with an imidazoline moiety differed from those with phenylethylamines, and yohimbine had a different antagonistic activity against these agonists $(10-13)$. In fact. Tayo (10) and Mottram (11) reported that yohimbine acted as a competitive antagonist against norepinephrine and clonidine, but the $\mathrm{pA}_{2}$-value for yohimbine using norepinephrine was one log unit lower than that obtained using clonidine. In the present study, the $p K_{B}$-value of yohimbine against norepinephrine was significantly one $\log$ unit lower than those obtained using a series of imidazolines. Therefore, our results also provide pharmacological evidence for the suggestion $(10,11)$ that there exist high and low affinity binding sites on alpha $2_{2}^{-}$ adrenoceptors in the rabbit vas deferens.

In conclusion, differences in the rank order of potency, affinity and relative efficacy of a series of imidazolines and differences in the affinity of yohimbine obtained from a series of imidazolines in the rabbit vas deferens and the guinea pig ileal longitudinai muscle indicate that the presynaptic alpha $a_{2}$-adrenoceptors in these tissues are not identical. Furthermore, data from our studies also add to increasing evidence of the existence of high and low binding sites on the alpha ${ }_{2}^{-}$ adrenoceptors.

\section{References}

1 Langer, S.Z.: Presynaptic regulation of catecholamıne release. Biochem. Pharmacol. 23, 1793$1800(1974)$

2 Berthelsen, S. and Pettinger, W.: A functional basis for classification of $\alpha$-adrenergic receptors. Life Sci. 21, 595-606 (1977)

3 Wikberg, J.E.S.: The pharmacological classification of adrenergic $\alpha_{1}$ arid $\alpha_{2}$ receptors and their mechanisms of action. Acta Physicl. Scand., Supp. 468, 1-99 (1979)

4 Wikberg, J.E.S.: Pre- and postjunctional $\alpha$ receptors. In Presynaptic Receptors, Edited by Langer, S.Z., Starke, K. and Dubocovich, M.L., p. 117-123. Pergamon Press, Oxford (1979)

5 Timmermans, P.B.M.W.M., Kwa, H.Y. and Van Zwieten, P.A.: Possible subdivision of postsynaptic $\alpha$-adrenoceptors mediating pressor responses in the pithed rat. Naunyn Schmiedebergs Arch. Pharmacol. 310, 189-193 (1979)

6 DeMey, J.G. and Vanhoutte, P.M.: Uneven distribution of postjunctional alpha - $^{-}$and alpha $_{2}$-like adrenoceptors in canine arterial and venous smooth muscle. Circ. Res. 48, 875-884 (1981)

7 Langer, S.Z. and Shepperson, N.B.: Recent developments in vascular smooth muscle pharmacology: the postsynaptic $\alpha_{2}$-adrenoceptor. Trends Pharmacol. Sci. 3, 440-444 (1982)

8 Langer, S.Z.: Presynaptic regulation of the release of catecholamines. Pharmacol. Rev. 32, 337-362 (1980)

9 Alabaster, V.A., Keir, R.F. and Peters, C.J.: 
Comparison of potency of $\alpha_{2}$-adrenoceptor antagonists in vitro: evidence for heterogeneity of $\alpha_{2}$-adrenoceptors. Br. J. Pharmacol. 88, 607$614(1986)$

10 Tayo, F.M.i Prejunctional inhibitory $\alpha$-adrenoceptors and dopaminoceptors of the rat vas deferens and the guinea-pig ileum in vitro. Eur. J. Pharmacol. 58, 189-195 (1979)

11 Mottram, D.R.: Pharmacological evidence for high affinity and low affinity $\alpha_{2}$-adrenoceptor binding sites in rat vas deferens. Arch. Int. Pharmacodyn. Ther. 264, 28-39 (1983)

12 Mottram, D.R. and Thakar, Y.: The action and interaction of $\beta$-phenylethylamines and imidazolines on prejunctional $\alpha_{2}$-adrenoceptors of guinea-pig ileum in the presence of the noncompetitive antagonist benextramine. J. Pharm. Pharmacol. 36, 668-672 (1984)

13 Bond, R.A., Charlton, K.G. and Clarke, D.E.: Responses to norepinephrine resistant to inhibition by alpha and beta adrenoceptor antagonists. J. Pharmacol. Exp. Ther. 236, 408-415 (1986)

14 Adebanjo, A.O. and Ambache, N.: Species variation in vas deferens motor transmission. J. Physiol. (Lond.) 281, 28P-29P (1979)

15 Ennis, C. and Lattimer, N.: Presynaptic agonist effect of phentolamine in the rabbit vas deferens and rat cerebral cortex. J. Pharm. Pharmacol. 36 , $753-757$ (1984)

16 Furchgott, R.F.: The classification of adrenoceptors (adrenergic receptors). An evaluation from the standpoint of receptor theory. In Catecholamines, Edited by Blaschko, H. and Muscholl, E., Vol. 33, p. 283-335, Springer Verlag. New York (1972)

17 Kenakin, T.P.: The classification of drugs and drug receptors in isolated tissues. Pharmacol. Rev. 36, 165-222 (1984)

18 Kenakin, T.P.: The quantification of relative efficacy of agonists. J. Pharmacol. Methods 13, 281-308 (1985)

19 Brown, J., Doxey, J.C. and Handley, S.: Effects of $\alpha$-adrenoceptor agonists and antagonists and cf antidepressant drugs on pre- and postsynaptic $\alpha$-adrenoceptors. Eur. J. Pharmacol. 67, 33-40 (1980)

20 Wikberg, J.E.S.: Pharmacological classification of adrenergic receptors in the guinea pig. Nature 273, 164-166 (1978)

21 Paton, D.W.M. and Aboozar, M.: The origin of acetylcholine released from guinea-pig intestine and longitidinal muscle strips. J. Physiol. (Lond.) 194, 13-33 (1968)

22 Melchiorre, C.: Tetramine disulfides: A new tool in $\alpha$-adrenergic pharmacology. Trends Pharmacol. Sci. 2, 209-211 (1981)

23 Furchgott, R.F. and Burztyn, P.: Comparison of dissociation constants and relative efficacies of selective agonists actirig on parasympathetic receptors. Ann. N.Y. Acad. Sci. 144, 882-893 (1967)

24 Belis, J.A., Colby, J.E. and Westfall, D.P.: Effects of $\alpha$-adrenoceptor agents on norepinephrine release from vas deferens of several species including man. Eur. J. Pharmacol. 78, 487-490 (1982)

25 Nahorsky, S.R., Barnett, D.B. and Cheung, Y.D.: Alpha-adrenoceptor-effector coupling: affinity states or heterogeneity of the alpha ${ }_{2}$-adrenoceptor? Clin. Sci. 68, 39s-42s (1985)

26 Neylon, C.B. and Summers, R.J.: [ ${ }^{3} \mathrm{H}$ ]-rauwolscine binding to alpha ${ }_{2}$ adrenoceptors in the mammalian kidney: apparent receptor heterogeneity between species. Br. J. Pharmacol. 85, 349-359 (1985)

27 Waterfall, J.F., Rhodes, K.F. and Lattimer, N.: Studies of $\alpha_{2}$-adrenoceptor antagonist potency in vitro: Comparisons in tissue from rats, rabbits, dogs and humans. Clin. Sci. 68, 21s-24s (1985)

28 Wikberg, J.E.S. and Lefkowitz, R.J.: Alpha adrenergic receptors are located prejunctionally in the Auerbach's plexus of the guinea pig small intestine: Direct demonstration by radioligand binding. Life Sci. 31, 2899-2905 (1982)

29 Paton, W.D.M. and Vizi, E.S.: The inhibitory action of noradrenaline and adrenaline on acetylcholine output by guinea-pig jleum longitudinal muscle strip. Br. J. Pharmacol. 35, $10-28(1969)$ 